\title{
Primulina anisocymosa (Gesneriaceae), a new species with a unique inflorescence structure from Guangdong, China
}

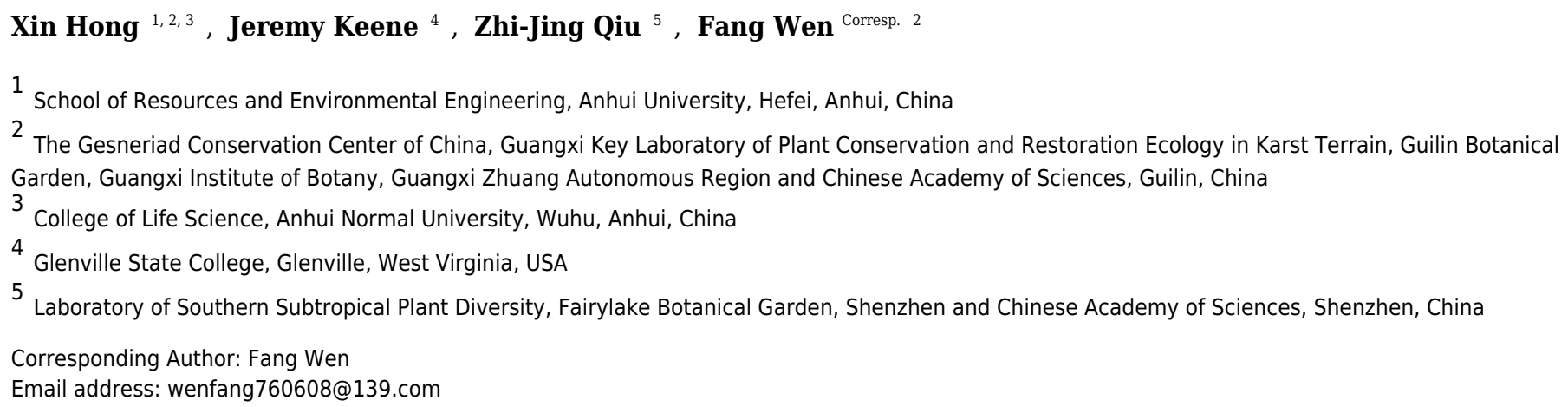

A new Primulina species from Guangdong, China with an unusual inflorescence is described here. Primulina anisocymosa is vegetatively most similar to P. bobaiensis. It can be distinguished from all species within Primulina morphologically by its unique zigzag monochasial cyme and infructescence. To confirm the phylogenetic relationships and generic placement of this species, not only morphological anatomical features but also chromosome and DNA sequence data were examined and analysed here. Two samples from different populations identified as Primulina anisocymosa are monophyletic and were nested in a monophyletic clade within Primulina with high branch support. The somatic chromosome number of the new species is also reported $(2 n=36)$, supporting its placement in the genus. 
1 Primulina anisocymosa (Gesneriaceae), a new species with a unique inflorescence structure

2 from Guangdong, China

3

4 Xin Hong ${ }^{1,2,3}$, Jeremy Keene ${ }^{4}$, Zhi-Jing Qiu ${ }^{5}$, Fang Wen ${ }^{2}$

5

$6{ }^{1}$ School of Resources and Environmental Engineering, Anhui University, Hefei, China.

72 The Gesneriad Conservation Center of China, Guangxi Key Laboratory of Plant Conservation 8 and Restoration Ecology in Karst Terrain, Guilin Botanical Garden, Guangxi Institute of Botany, 9 Guangxi Zhuang Autonomous Region and Chinese Academy of Sciences, Guilin, China.

$10{ }^{3}$ College of Life Science, Anhui Normal University, Wuhu, China.

$11{ }^{4}$ Glenville State College, 200 High Street, Glenville, West Virginia 26351, USA.

$12{ }^{5}$ Laboratory of Southern Subtropical Plant Diversity, Fairylake Botanical Garden, Shenzhen and 13 Chinese Academy of Sciences, Shenzhen, China.

16 Corresponding author:

17 Fang Wen ${ }^{4}$

18 Email address: wenfang760608@139.com. 
ABSTRACT

21

A new Primulina species from Guangdong, China with an unusual inflorescence is described here. Primulina anisocymosa is vegetatively most similar to $P$. bobaiensis. It can be distinguished from all species within Primulina morphologically by its unique zigzag monochasial cyme and infructescence. To confirm the phylogenetic relationships and generic placement of this species, not only morphological anatomical features but also chromosome and DNA sequence data were examined and analysed here. Two samples from different populations identified as Primulina anisocymosa are monophyletic and were nested in a monophyletic clade within Primulina with high branch support. The somatic chromosome number of the new species is also reported $(2 n=36)$, supporting its placement in the genus.

\section{INTRODUCTION}

Primulina Hance (Didymocarpinae: Gesneriaceae) was originally described as a monotypic genus with P. tabacum Hance the only known species (Wang et al. 1998; Li and Wang 2004;

Zheng and Xia 2005; Wei et al. 2010). Primulina was recently expanded to include other Asian genera making the genus one of the largest within Gesneriaceae. The genus is distributed from southern China southward into central Vietnam (Möller et al. 2016) and comprises more than 174 recognized species. Thus far, only 19 species are reported from Vietnam, the remainder occur in China (Hộ 2000; Weber et al. 2011a; Möller et al. 2016).

Some recent studies have suggested that the vast majority of Primulina species grow on limestone in tropical and subtropical Karst areas (Xu 1993; Ai et al. 2015; Kang et al. 2014). 
41 Most of the known species from China and Vietnam share a similar inflorescence structure

42 (dichotomous cyme). This inflorescence is highly variable between species. Primulina diffusa

43 Xin Hong, Fang Wen, \& S.B. Zhou for example has a single-flowered cyme, which is an

44 extreme reduction of the dichotomous cyme (Li and Wang 2004; Wang et al. 1998; Wei et al. 2010). The significant variation in inflorescence structure and corolla morphologies suggests a

high degree of evolutionary lability, presumably driven by adaptation to different pollinators

(Weber et al. 2011b). Due to the wide variation in characteristics within the Asian genera it is difficult to ascertain a single synapomorphy for the genus (Chen et al. 2014). Thus, it is necessary to have molecular evidence to effectively place unique species in the right genus.

In 2009, we found a population of Primulina with only the previous year's fruit in Yangchun city, Guangdong province. Then the following year, Mr. Wei-Jun Wu (WJW) found the same purported species on another limestone hill near Gaozhou city, Guangdong province. We observed the species closely and noted that it was an undocumented species of Primulina, based infructescence which looked similar to a cincinnus, a determinate cymose inflorescence with a zigzag rachis. The following year, FW and WJW collected some specimens with flowers from analysed. After consulting the relevant literature (Wang et al. 1998; Hộ 2000; Li and Wang 2004; the same locality for study. They observed the development of the flowers and the unusual zigzag monochasial inflorescence and infructescence. To confirm the phylogenetic relationships and generic placement of this species, chromosome and DNA sequence data were collected and

61 Wei et al. 2010) along with the chromosome characteristics and molecular analysis, we 
62

concluded that this new species was assignable to Primulina (Weber et al. 2011a). We provide a description and illustration of the new species here.

\section{MATERIALS AND METHODS}

\section{Ethics statement}

conservation area and no specific permissions were required for these locations. Since the species are currently undescribed, they are not currently included in the China Species Red List (Wang \& Xie 2004). Our field studies did not involve any endangered or protected species. No specific permits were required for the present study.

\section{Nomenclature}

The electronic version of this article in Portable Document Format (PDF) will represent a published work according to the International Code of Nomenclature for algae, fungi, and plants (ICN), hence the new names contained in the electronic version are effectively published under that Code from the electronic edition alone. In addition, new names contained in this work which have been issued with identifiers by IPNI will eventually be made available to the Global Names Index. The IPNI can be accessed and the associated information contained in this publication viewed through any standard web browser using the web address "http://ipni.org/". The online version of this work is archived and available from the following digital repositories: PeerJ, PubMed Central, and CLOCKSS. 


\section{Material collection}

The new species has been monitored in the field and nursery of The Gesneriad Conservation Center of China (GCCC) by the authors since the plants were collected. We collected leaf materials of this possible new species, using silica gel to dry them in the field for DNA extraction.

\section{Morphological observations and specimens examined}

A study of the genus Primulina from S and SW China and adjacent areas of Vietnam was undertaken. All available specimens of Primulina stored in the following herbaria from China, Vietnam, United States and the United Kingdom were examined: E, GH, HN, IBK, IBSC, K, MO, KUN, PE, US and VMN ((herbarium acronyms according to Index Herbariorum; Thiers 2017). All morphological characters were studied using a dissecting microscope (SZX16, Olympus, Tokyo, Japan). Characters were described using the terminology presented by Wang et al. (1998) were applicable. The morphological comparison with other species was based on study of live plants in the field and in cultivation in GCCC, herbarium specimens, and also information gathered in the literature searches.

\section{DNA extraction and PCR}

The DNA was extracted using a DNeasy plant mini kit (Qiagen, Crawley, UK) following the manufacturer's protocol. The extractions were checked for quality and quantity using a RapidHIT200 (IntegenX, Pleasanton, CA, USA). Total genomic DNA was used as the template for polymerase chain reactions (PCR). The PCR conditions and cycle sequencing reactions followed Möller et al. (2009, 2011). 


\section{Phylogenetic analyses}

For the phylogenetic analyses, sequences were newly acquired for each population of this new species and also the morphologically similar species P. bobaiensis Li, Pan and Zhang (Table 1), were added to a reduced Old World Gesneriaceae matrix of Middleton et al. $(2014,2015)$ and the matrices realigned manually. The resulting matrix contained 185 samples (177 species) with 26 species of Primulina included, covering all 39 genera currently recognized in the advanced Asiatic and Malesian Gesneriaceae at present (Möller et al. 2009, 2011; Weber et al. 2013; Middleton et al. 2014, 2015). The tree was rooted with the outgroup taxon Tetraphyllum (Möller et al. 2009). Data for the phylogenetic analyses were downloaded from GenBank (https://www.ncbi.nlm.nih.gov/genbank/). Species, voucher information, and NCBI accession numbers are listed in Appendix 1.

$$
\text { Combinability of the ITS and trnLF datasets were investigated by the incongruence length }
$$
difference (ILD) test (Farris et al. 1995a, b), implemented in PAUP* 4.0a146 (Swofford 2002) as a partition-homogeneity test (PHT). Phylogenetic analyses were performed using Bayesian inference (BI) following Möller et al. (2011) and Weber et al. (2011a). The model GTR + I + G was selected as the optimal model for both DNA regions based on the the Akaike Information Criterion (AIC; Akaike 1974) in MrModeltest version 2.3 (Nylander 2004). Bayesian inference analyses were carried out in MrBayes version 3.2.2 (Ronquist and Huelsenbeck 2003). Two independent analyses of 10,000,000 generations each were run with four Markov chain Monte Carlo (MCMC) chains and a tree sampled at every 1000th generation. The first 10 percent of the generations were discarded as burn-in and Bayesian Posterior probabilities (BPP) obtained from 
124 the analysis were used to indicate the support for various branches.

\section{Chromosome preparations}

126 Seeds for chromosome analysis were collected from the two wild populations in 2012.

127 Voucher specimens (vouchered as: Fang Wen 201090406-1, SLY160515-01) have been

128

129

130

131

132

133

134

135

136

137

138

139

140

141

142

143

144 deposited in IBK. Root tips were collected from leaf-cuttings started in vermiculite in the culture room at GCCC. Usable roots were gathered and pretreated in $2 \mathrm{mM}$ 8-hydroxyquinoline at 15$18^{\circ} \mathrm{C}$ for about $6 \mathrm{~h}$, then fixed overnight in an ethanol-acetic acid solution $(3: 1)$ at $4{ }^{\circ} \mathrm{C}$. The root tips were macerated with $1 \mathrm{~N}$ hydrochloric acid (10:1). The root tips were then stained and squashed in 2\% acetic orcein. Metaphase plates were photographed using an Olympus BX51 microscope with Olympus DP71 camera attachment (Olympus, Tokyo, Japan). The chromosome numbers were determined in at least 20 cells with well-spread chromosomes of 10 different root tips from the two known populations.

\section{RESULTS}

\section{Molecular phylogenetic studies}

The data matrix was assembled and included 1381 characters, including 608 for ITS and 773 for $\operatorname{trn} \mathrm{L}-\mathrm{F}$. The results did not indicate incongruent phylogenetic signals $(\mathrm{P}=0.36)$ and the two matrices were analysed together. The phylogenetic tree (Fig. 1) was highly resolved with a topology consistent with previous phylogenetic analyses by Middleton et al. $(2014,2015)$. The new species was nested in a clade within Primulina with high branch support $(\mathrm{PP}=1.00)$. Two samples from different populations identified as Primulina anisocymosa are monophyletic $(\mathrm{PP}=$ 
145 1.00). The new species was strongly supported in a clade $(\mathrm{PP}=1.00)$ comprised of Primulina

146 gemella (D. Wood) Y.Z. Wang and its morphologically most similar congener P. bobaiensis.

\section{Chromosome characteristics}

148 The chromosome size of Primulina was measured and noted as small with a range from $0.6-$

$1492.4 \mu \mathrm{m}$ (Lima-de-faria 1980; Yang et al. 2012). The somatic chromosomes at metaphase of $P$. anisocymosa were photographed (Fig. 2) and determined to be diploid with $2 n=36$.

151

152

153

154

155

156

157

158

159

160

161

162

163

164

165

\section{Taxonomic treatment}

Primulina anisocymosa F. Wen, Xin Hong \& Z.J. Qiu, sp. nov. (Figs 3, 4)

\section{IPNI:}

Type. China. Guangdong: Gaozhou city, rocky crevices in moist shady cliffs on a red sedimentary rock hill, elevation ca. 120 m, 20 Nov. 2012, F. Wen 20121120 (holotype IBK!; isotype ANU!).

Additional collections. China. Guangdong: Yangchun, ca. 107 m, 06 April 2009, Fang Wen 201090406-1 (IBK!; ANU!); China. Guangxi, cultivated in nursery of GCCC, Guilin Botanical Garden, introduced from Gaozhou city, growing on rocky crevices in moist shady cliffs on a red sedimentary rock hill, elevation ca. $120 \mathrm{~m}$, SLY160515-01 (IBK!).

Diagnosis. Primulina anisocymosa differs from other congeners by the presence of a zigzag monochasial cyme.

Description. Perennial herb, acaulescent. Rhizome subterete, 1-3 cm long, 1.5-2 cm diam, glabrous. Leaves 6-9 or more, 3-whorled, basal; sessile or subsessile. Leaf blade slightly fleshy, dried papery, oblong-rhombic, or elliptic-oblong, 3-9(-12) × 2.5-6(-8) cm, apex obtuse or 
166

167

sometimes rounded, base cuneate to attenuate, and decurrent into slightly broad wings of extremely inconspicuous petiole, or nearly sessile, margin distinctly serrate with $6-8$ triangular serration on each side; densely pubescent intermixed with sparsely villous trichomes on both surfaces, lateral veins 4-7 on each side, impressed adaxially and prominent abaxially. Cyme monochasial, reduced with 4-6 (-10) or more cymules alternating along rachis (appearing zigzag), 3-6 flowers per cymule. Peduncles 15-20 cm long, ca. $2 \mathrm{~mm}$ in diameter, pubescent intermixed sparsely with glandular trichomes. The inflorescence has only one of the two lateral paraclades of the pair-flowered cyme extended. The others are reduced to the point of pedicel attachment and form the swollen nodules at the base of 2-3(-5) flowers. All flowers of each cymule clustered and each cluster facing away from the rachis. Bracts variable, usually 1-2, occasionally 3 , sometimes withered when flowering, free, narrowly triangular, $2-3 \times \mathrm{ca} .1 \mathrm{~mm}$, outside puberulent, inside verrucose and glabrous, margin entire, apex acute, aligned on one side of the rachis; bracteoles three, subulate, $1 \times$ ca. $0.2 \mathrm{~mm}$, not-paired, aligned on one side at the base of pedicel. Pedicels extended only on one side, $18-20 \mathrm{~mm}$ long, ca. $1.0 \mathrm{~mm}$ in diameter, densely glandular-puberulent. Calyx 5 lobed from base; segments equal, lanceolate-oblong, 5-8 $\times$ 4-5 mm, outside densely puberulent, inside verrucose and glabrous, margin entire, apex acute. Corolla ca. $1.5 \mathrm{~cm}$ long, purpe, upper part of the interior of the corolla with two dark brown short stripes; mouth 0.6-0.8 cm diam, outside glandular-pubescent, inside glabrous; tube nearly infundibuliform, ca. $1.3 \mathrm{~cm}$, limb distinctly 2-lipped, adaxial lip 2-parted for over half its length, lobes obliquely ovate, ca. $0.5 \mathrm{~cm}$ long, $0.3-0.4 \mathrm{~cm}$ in diameter at base, abaxial lip 3-parted to the base, central lobe ovate oblong, $0.5-0.6 \mathrm{~cm}$ long, $0.25-0.35 \mathrm{~cm}$ in diameter, lateral ones 
187 188

obliquely oblong. Stamens 2, adnate to ca. $6 \mathrm{~mm}$ above the corolla base; filaments ca. $6 \mathrm{~mm} \mathrm{long}$, glandular-pubescent, geniculate at the base, anthers fused by their entire adaxial surfaces, elliptic, ca. $2 \mathrm{~mm}$ long, yellowish brown, glabrous; staminodes two, linear, ca. $3 \mathrm{~mm}$ long, glabrous, adnate to ca. $7 \mathrm{~mm}$ above the corolla base; capitate at apex. Disc annular, ca. $1 \mathrm{~mm}$ high, margin entire. Ovary linear, $0.9-1.1 \mathrm{~cm}$ long, ca. $2 \mathrm{~mm}$ in diameter, densely glandular- and eglandularpuberulent; style green, ca. $6 \mathrm{~mm}$ long, ca. $0.8 \mathrm{~mm}$ in diameter, glandular-puberulent. Stigma translucent to green, obtrapeziform, apex retuse, ca. $1.2 \mathrm{~mm}$ long. Capsule linear, $4-4.5 \mathrm{~cm}$ long, ca. $2 \mathrm{~mm}$ in diameter, glandular- and eglandular-puberulent. Seeds long-ellipsoidal, dark brown, mammillate on the surface.

Distribution. The new species is known from two locations: Gaozhou City and Yangchun City, Guangdong Province, southern China. This area is in the transitional zone between the tropics and subtropics.

Habitat and ecology. Primulina anisocymosa is locally abundant in Yangchun, although very rare in Gaozhou, Guangdong. The total number of this species in Gaozhou does not exceed 100 individuals. It grows in rocky crevices of moist shady cliffs on a red sedimentary rock hill, at an elevation of $50 \mathrm{~m}$ a.s.l in Gaozhou City. The species also grows on the moist rock surface of limestone cave entrances in Yangchun. The average annual temperature of the two localities is similar (ca. $21^{\circ} \mathrm{C}$ ) and the average annual precipitation is around $2380 \mathrm{~mm}$. P. anisocymosa occurs in subtropical evergreen broad-leaved forest. Flowering from September to October and fruiting from October to December.

Etymology. The scientific name is derived from its unusual zigzag monochasial cyme. The latin 
208 prefix, "aniso-", means different, uneven or asymmetrical; "cyma" refers to the predominant

209 inflorescence type seen in Primulina a pair-flowered cyme.

210

211

\section{DISCUSSION}

212

The size of $P$. anisocymosa chromosomes is within the above-mentioned range for the genus.

At present, almost all known chromosome numbers in this genus appear to represent a diploid

number with a basic number of $x=18$, except the polyploid $P$. longgangensis (Wang) Liu and

Wang with $2 n=72$ (Christie et al. 2012, Möller et al. 2002 onwards). Our chromosome counts

of $(2 n=36)$ for $P$. anisocymosa corresponds with known chromosome number $(x=18)$

supporting its generic placement in Primulina.

The pair-flowered cyme is the basic type of inflorescence in the Old World Gesneriaceae

219 (Weber 1978, 1982). The inflorescences in Primulina are usually dichotomous cymes with few

to many flowers or simplified single-flowered cymes (Li and Wang 2004; Wang et al. 1998;

Chen et al. 2008; Wei et al. 2010). The development of pair-flowered cymes shows that the main

axis of the inflorescence has a true terminal flower and a front flower. Two lateral paraclades

arise in the axils of two opposite lateral bracts below the terminal flower, the following branches

continuously repeat the same pattern (Weber 1978, 1982, 2013; Wang and Li 2002; Li and Wang

2004). This new species has an inflorescence morphology unlike any other described Primulina

species to date.

The branching morphology of the inflorescences of this new species is a zigzag monochasial

branching structure. The inflorescence has only one of the two lateral paraclades of the pair- 
229 flowered cyme extended. The others are reduced to the point of pedicel attachment and form the

230 swollen nodules at the base of $2-3(-5)$ flowers. Each flower cluster whorl turns in the direction

231 of the main axis and flowering continues upward in an acropetal sequence. Frthermore, the

232 markedly special character of inflorescence in two known populations is very stable, as long as

233 the plants grow normally. This is morphologically distinctive from all known Primulina species.

234 The zigzag monochasial inflorescence and infructescence of Primulina anisocymosa is so

235 peculiar that we can easily distinguish it from other known species in the genus. It

236 morphologically resembles P. bobaiensis (see Fig. 5) in having similar corolla shape and color.

237 Both species are found in southern China (Guangdong and Guangxi), but Primulina anisocymosa 238 can be easily distinguished by the inflorescence architecture.

\section{ACKNOWLEDGEMENTS}

The authors are grateful to Ms. Xiao-Ming Xu and Ms. Wen Ma for drawing the handsome illustration. The authors also should like to thank Mr. Wei-Jun Wu for his advice on the living specimen collection.

REFERENCES

Ai B, Gao Y, Zhang X, Tao J, Kang M, Huang H. 2015. Comparative transcriptome resources 
249 Akaike H. 1974. A new look at the statistical model identification. IEEE Transactions on Automatic Control 19: 716-723.

251

252

253

254

255

256

257

258

259

260

261

262

263

264

265

266

267

268

269

Chen WH, Möller M, Shui YM, Zhang MD. 2008. A new species of Paraboea (Gesneriaceae) from a karst cave in Guangxi, China, and observations on variations in flower and inflorescence architecture. Botanical Journal of the Linnean Society 158: 681-688.

Chen WH, Möller M, Shui YM, Hong W, Yang JB, Li GY. 2014. Three new species of Petrocodon (Gesneriaceae), endemic to the limestone areas of southwest china, and preliminary insights into the diversification patterns of the genus. Systematic Botany 39: $316-330$.

Christie F, Barber S, Möller M. 2012. New chromosome counts in Old World Gesneriaceae: numbers for species hitherto regarded as Chirita, and their systematic and evolutionary significance. Edinburgh Journal of Botany 69: 323-345.

Farris J, Källersjö SM, Kluge AG, Bult C. 1995a. Constructing a significance test for incongruence. Systematic Biology 44: 570-572.

Farris J, Källersjö SM, Kluge AG, Bult C. 1995b. Testing significance of incongruence. Cladistics 10: 315-319.

Hộ PH. 2000. Chirita (Gesneriaceae). Pp. 19-24 in Cây cỏ Việt Nam (An Illustrated Flora of Vietnam) Quyến III. ed. Hộ PH. Montreal: Mekong Printing.

Kang M, Tao JJ, Wang J, Ren C, Qi QW, Xiang QY, Huang HW. 2014. Adaptive and nonadaptive genome size evolution in Karst endemic flora of China. New Phytologist 202: $1371-1381$. 
270

271

272

273

274

275

276

277

278

279

280

281

282

283

284

285

286

287

288

289

290

Li ZY, Wang YZ. 2004. Primulina, Chirita and Chiritopsis. Pp. 170-282. in Plants of

Gesneriaceae in China. eds. Li ZY, Wang YZ. Zhengzhou: Henan Science and

Technology Publish House.

Lima-de-faria A. 1980. Classification of genes, rearrangements and chromosomes according to the chromosome field. Hereditas 93: 1-46.

Middleton DJ, Atkins H, Truong LH, Nishii K, Möller M. 2014. Billolivia, a new genus of Gesneriaceae from Vietnam with five new species. Phytotaxa 161, 241-269.

Middleton DJ, Nishii K, Puglisi C, Forrest LL, Möller M. 2015. Chayamaritia, (Gesneriaceae: Didymocarpoideae), a new genus from Southeast Asia. Plant Systematics and Evolution 301, 1-20.

Möller M, Forrest A, Wei YG, Weber A. 2011. A molecular phylogenetic assessment of the advanced Asiatic and Malesian Didymocarpoid Gesneriaceae with focus on nonmonophyletic and monotypic genera. Plant Systematics and Evolution 292: 223-248.

Möller M, Pfosser M, Jang CG, Mayer V, Clark A, Hollingsworth ML, Barfuss MHJ, Wang YZ, Kiehn M, Weber A. 2009. A preliminary phylogeny of the 'Didymocarpoid Gesneriaceae' based on three molecular data sets: incongruence with available tribal classifications. American Journal of Botany 96: 989-1010.

Möller M, Pullan M, Kiehn M, Skog LE. 2002. RBGE 'WebCyte' - Gesneriaceae cytology database, Edinburgh, Scotland: The Royal Botanic Garden Edinburgh. Available from: http://www.rbge.org.uk/rbge/web/search/index.jsp.

Möller M, Wei YG, Wen F, Clark JL, Weber A. 2016. You win some you lose some: Updated 
generic delineations and classification of Gesneriaceae - Implications for the family in China. Guihaia 36: 44-60.

293

294

295

296

297

298

299

300

301

302

303

304

305

306

307

308

309

310

311

Nylander JAA. 2004. MrModeltest v2. Program distributed by the author. Uppsala:

Evolutionary Biology Centre, University of Uppsala.

Swofford DL. 2002. PAUP*: Phylogenetic Analysis Using Parsimony (*and other methods), ver. 4. UK, MA: Sinauer.

Ronquist F, Huelsenbeck JP. 2003. MrBayes 3: Bayesian phylogenetic inference under mixed models. Bioinformatics 19: 1572-1574.

Thiers B. 2017. Index Herbariorum: a global directory of public herbaria and associated staff. New York Botanical Garden’s Virtual Herbarium. http:// sweetgum.nybg.org/science/ih/. Accessed 10 Oct 2017

Wang S, Xie Y. 2004. China species red list vol. 1: Red List. Beijing: Higher Education Press.

Wang WT, Pan KY, Li ZY, Weitzman AL, Skog LE. 1998. Gesneriaceae. Pp. 268-272 in Flora of China vol. 18, eds. Wu ZY, Raven PH. Beijing: Science Press, and St. Louis: Missouri Botanic Garden.

Wang YZ, Li ZY. 2002. Inflorescence development of Whytockia (Epithemateae, Gesneriaceae) and phylogenetic implications within Gesneriaceae. Plant Systematics and Evolution 236: 45-54.

Weber A. 1978. Transition from pair-flowered to normal cymes in Gesneriaceae. Notes from the Royal Botanic Garden, Edinburgh 36: 355-368.

Weber A. 1982. Evolution and radiation of the pair-flowered cyme in Gesneriaceae. Australian 
Systematic Botany Society Newsletter 30: 23-41.

313 Weber A. 2013. Pair-flowered cymes in the Lamiales: structure, distribution and origin. Annals of Botany 112: 1577-1595.

Weber A, Clark JL, Möller M. 2013. A new formal classification of Gesneriaceae. Selbyana 31: 68-94.

\section{Weber A, Middleton DJ, Forrest A, Kiew R, Lim CL, Rafidah AR, Sontag S, Triboun P,} Wei YG, Yao TL, Möller M. 2011a. Molecular systematics and remodelling of Chirita and associated genera (Gesneriaceae). Taxon 60: 767-790.

Weber A, Wei YG, Puglisi C, Wen F, Mayer V, Möller M. 2011b. A new definition of the genus Petrocodon (Gesneriaceae). Phytotaxa 23: 49-67.

Wei YG, Wen F, Möller M, Monro A, Zhang Q, Gao Q, Mou HF, Zhong SH, Cui C. 2010. Gesneriaceae of South China. Nanning: Guangxi Sciences and Technology Publishing House.

Xu ZR. 1993. A study of the limestone forest flora of southern and southwestern China. Guihaia (Supplemental Studies of the Limestone Foresty in China) 4: S5-S54.

Yang XY, Liang KM, Zhang XH, Ma GH. 2012. Karyotype Analysis of an endemic species Primulina tabacum (Gesneriaceae). Plant Diversity and Resources 34: 25-27.

Zheng YL, Xia NH. 2005. Gesneriaceae. Pp. 249-289 in Flora of Guangdong vol. 6. ed. Wu TL. Guangzhou: Guangdong Science and Technology Press. 
Figure 1

Molecular result showing two populations of this new species was strongly supported in a clade, and fell deeply nested in a monophyletic Primulina.

Bayesian inference tree focusing on Primulina inferred from combined trnL- $F+$ ITS data, Bayesian posterior probabilities values less than 1.00 are labeled along branches, all other nodes had PP values of 1.00. (GZ: type locality, Gaozhou city; YC: Yangchun city)

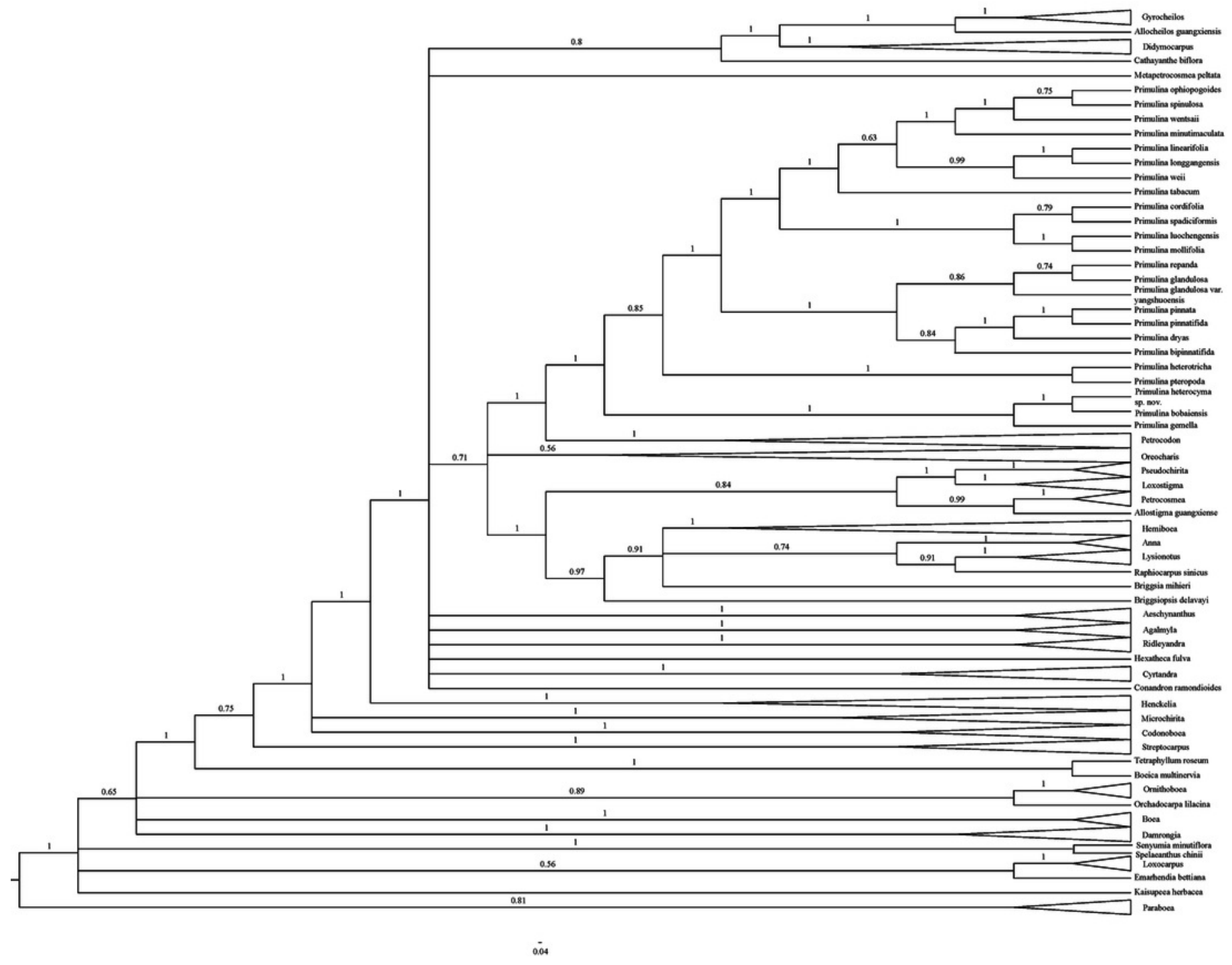


Figure 2

Somatic chromosomes at metaphase of Primulina anisocymosa

Somatic chromosomes at metaphase of Primulina anisocymosa ( $2 n=36$, from the leaf

cuttings). A, B, C. Microphotograph from different cells (A, B: Gangzhou, E: Yangchun). D, E:

Photomicrographs of mitotic metaphase chromosomes (D: Gangzhou, E: Yangchun). Photos by Ms. Sun-Lan Yin.

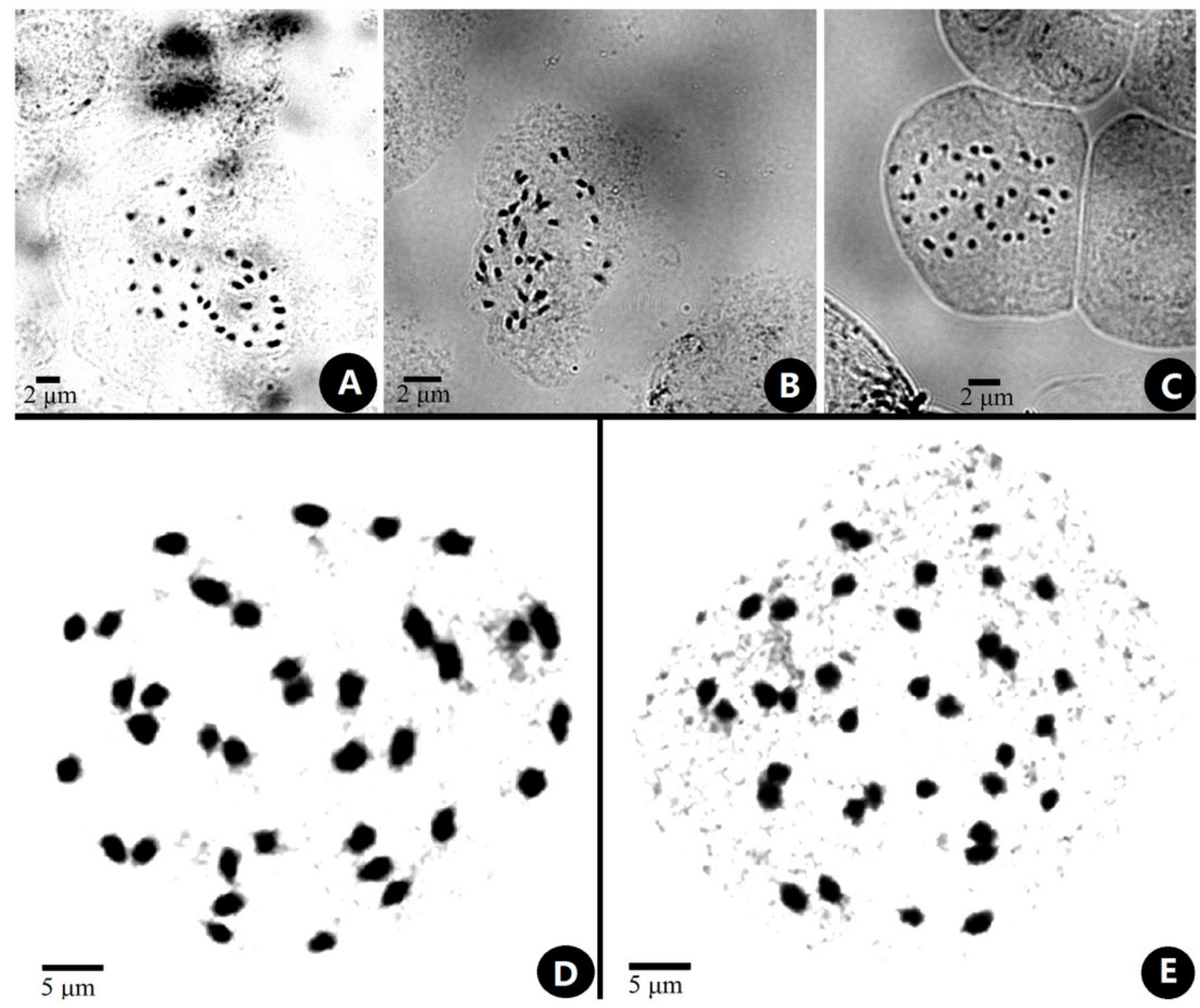




\section{Figure 3}

Line-drawing of Primulina anisocymosa

Primulina anisocymosa F. Wen, Xin Hong and Z.J. Qiu. A. Plant in flower. B. Corolla opened showing stamens and staminodes. C. Calyx and pistil with ovary, style and stigma. D. Seed.

- Drawn by Ms. Xiao-Ming Xu and Ms. Wen Ma. 


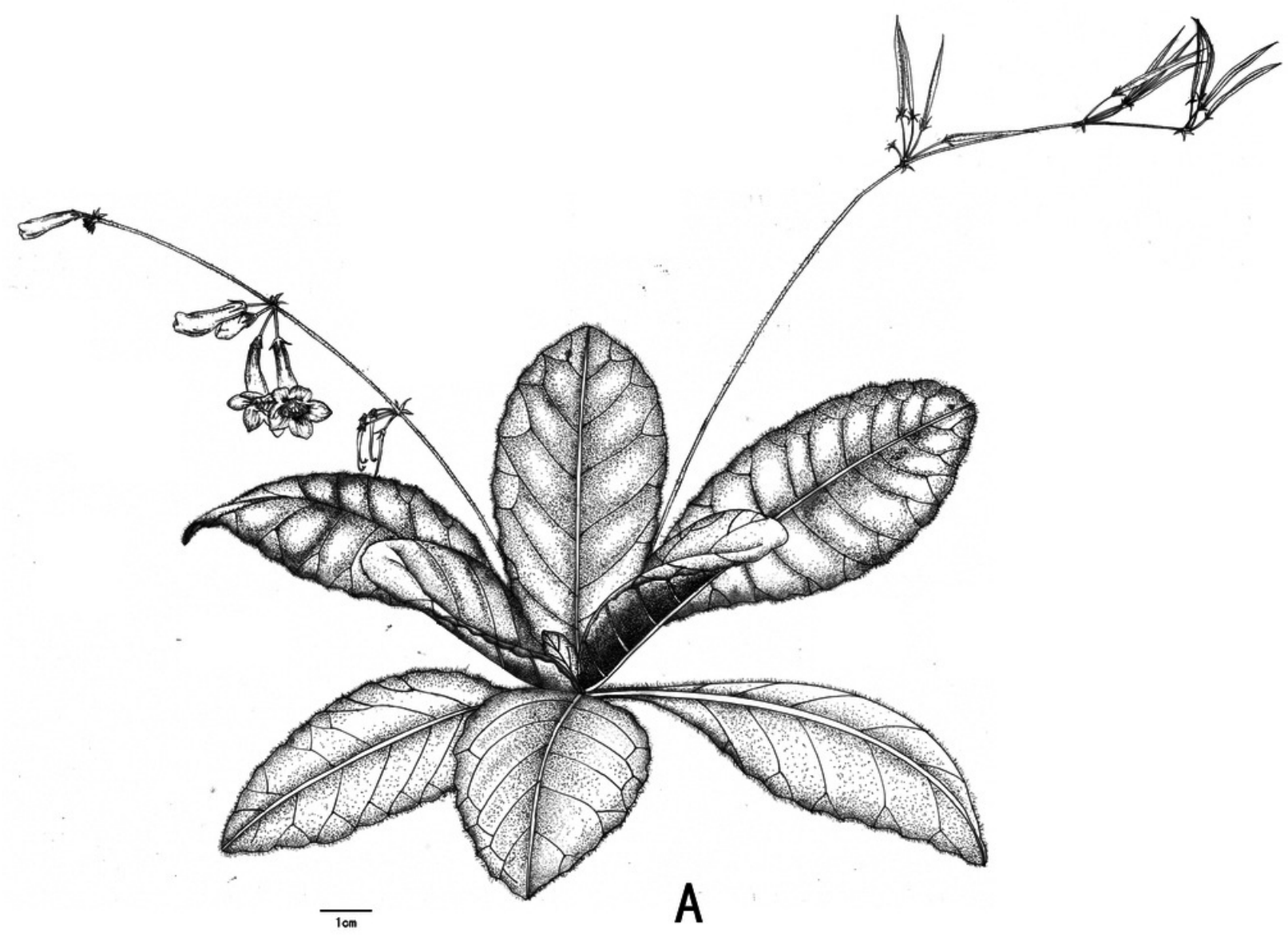

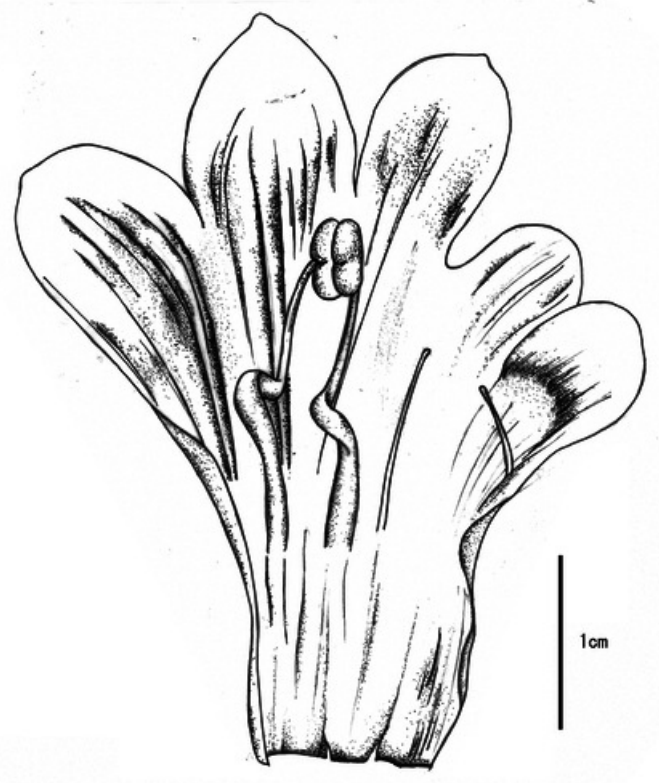

B

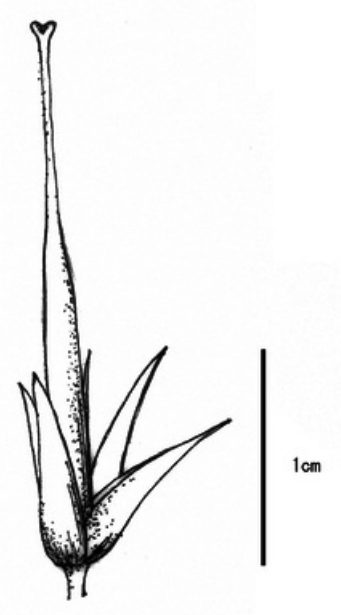

C

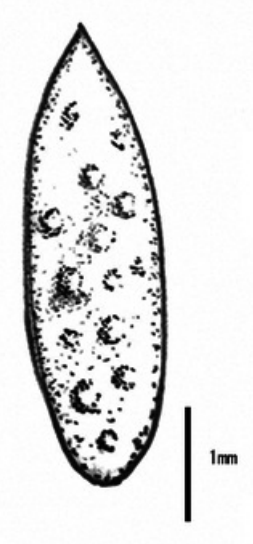

D 


\section{Figure 4}

Photos of Primulina anisocymosa two populations in natural habitat

Primulina anisocymosa (F. Wen, Xin Hong and Z.J. Qiu) A, B. Habitat (A. Gaozhou; B.

Yangchun) C, D. Vegetative part of plants (C. Yangchun; D. Gaozhou) E. Bracteoles, showing not-paired, aligned on one side at the base of pedicel. F. Cymule, reduced to the point attachment and forming swollen nodules at the base. G. Zigzag monochasial infructescence. Photos by Fang Wen. 

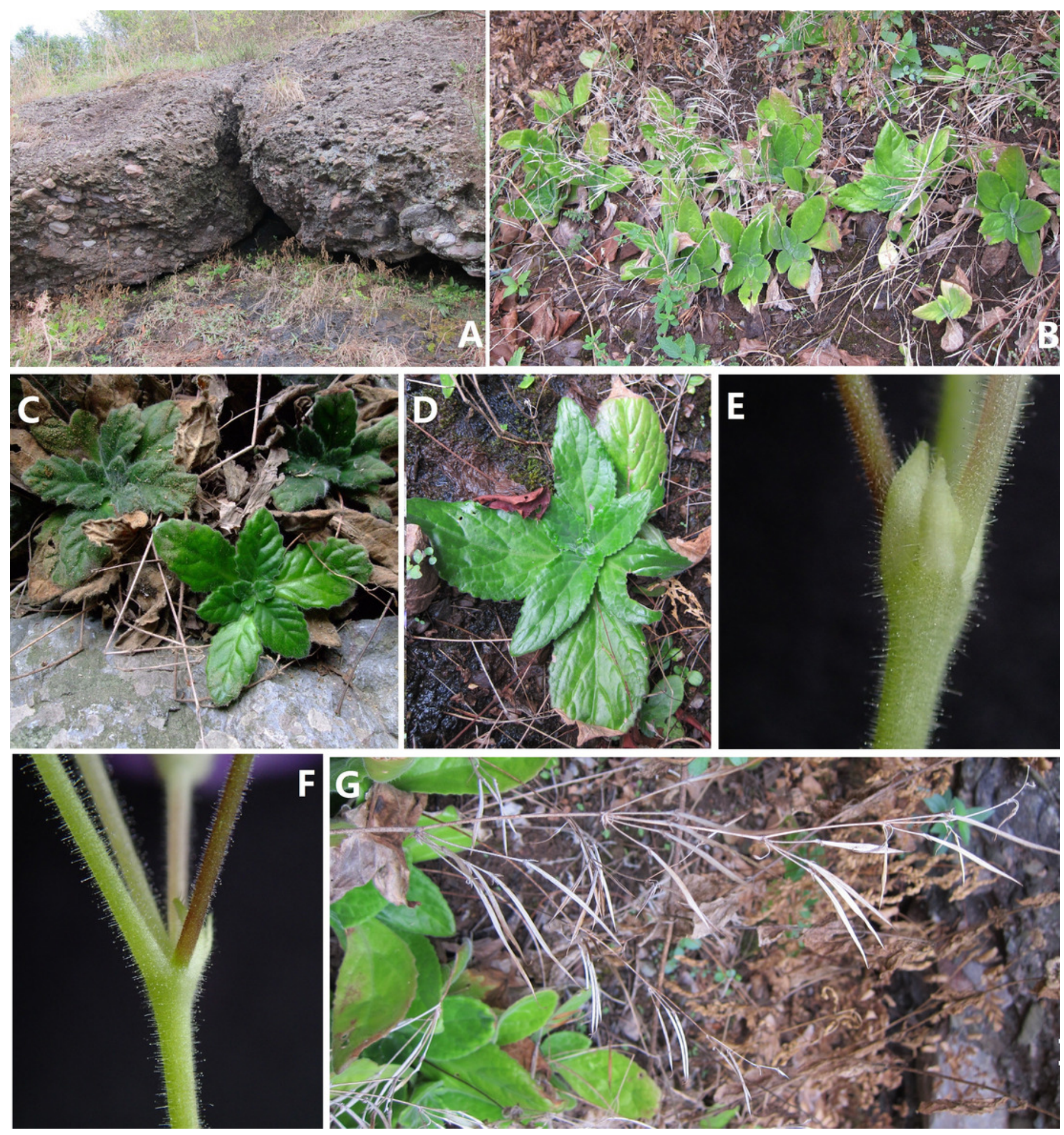


\section{Figure 5}

Comparison of Primulina anisocymosa and P. bobaiensis

Comparison of Primulina anisocymosaand $P$. bobaiensis, A. Habit of $P$. anisocymosa when in flower. B. A. Habit of $P$. bobaiensis when in flower. C. Adaxial leaf blades (left:P. bobaiensis, right: $P$. anisocymosa). D. Abaxial leaf blades (left:P. bobaiensis, right: $P$. anisocymosa). E. Cymes (upper: $P$. anisocymosa, lower:P. bobaiensis). F. Bracts (left:P. anisocymosa, right: $P$. bobaiensis). G. Frontal view of corolla of $P$. anisocymosa. H. Frontal view of corolla of $P$. bobaiensis. I. Top view of corolla (left:P. anisocymosa, right: P. bobaiensis). J. Lateral view of corolla of $P$. anisocymosa. K. Lateral view of corolla of $P$. bobaiensis. L. Opened corolla of $P$. anisocymosa. M. Opened corolla of $P$. bobaiensis. N. Pistils without corolla (left:P. anisocymosa, right: P. bobaiensis). Photoed by Xin Hong and Fang Wen. 

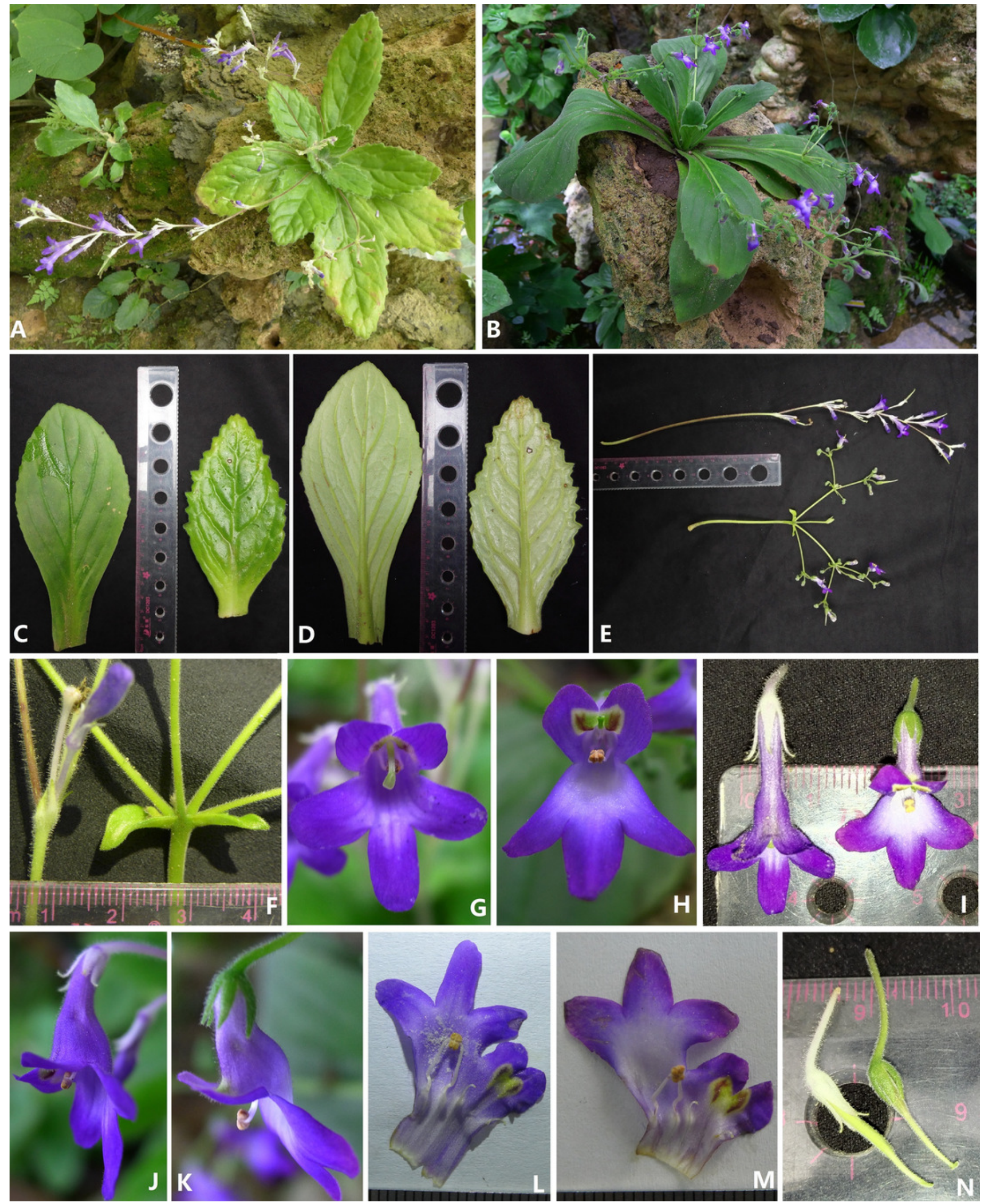


\section{Table $\mathbf{1}$ (on next page)}

Diagnostic character differences between Primulina anisocymosa and its close relative P. bobaiensis. 
1 Table 1. Diagnostic character differences between Primulina anisocymosa and its close relative P. bobaiensis.

\begin{tabular}{|c|c|c|}
\hline characters & P. anisocymosa & P. bobaiensis \\
\hline Petiole & Sessile or subsessile & Petiolate, 3-12 mm long \\
\hline \multirow[t]{4}{*}{ Leaf blade shape } & Oblong-rhombic, or elliptic-oblong; base & Elliptic or oval; base cuneate \\
\hline & cuneate-attenuate, and decurrent into slightly & to broadly cuneate \\
\hline & broad wings of extremely inconspicuous & \\
\hline & petiole & \\
\hline \multirow[t]{2}{*}{ Leaf blade margin } & Obviously regularly $6-8$ triangle to obtuse- & Shallowly \\
\hline & triangle serrate from the base & serrate \\
\hline Indumentum of leaf & Densely pubescent and sparsely villous on both & Pubescent on both surfaces \\
\hline blade & surfaces & \\
\hline Peduncle indumentum & Pubescent sparsely glandular-pubescent & Pubescent \\
\hline \multirow[t]{4}{*}{ Bract } & $1-2(-3)$, usually withered when flowering, & Opposite, oblanceolate; $8-22$ \\
\hline & free, narrowly triangular; $2-3 \times$ ca. $1 \mathrm{~mm}$; & $\times 4-9 \mathrm{~mm}$; pubescent on both \\
\hline & outside puberulent, inside verrucose and & sides \\
\hline & glabrous & \\
\hline \multirow[t]{2}{*}{ Corolla } & Outside glandular pubescent, inside glabrous & Outside pubescent, inside \\
\hline & & sparsely puberulent \\
\hline Calyx lobes size & $5-8 \times 4-5 \mathrm{~mm}$ & $3-5 \times 0.8-1.1 \mathrm{~mm}$ \\
\hline Filaments indumentum & Glandular pubescent & Glabrous \\
\hline Staminodes & 2 & 3 \\
\hline
\end{tabular}

